\title{
Improving Learning Performance by Providing Intellectual Suggestions
}

\author{
Al-Sarem Mohammed \\ Département d'informatique \\ FST Mohammedia \\ Mohammedia, Maroc
}

\author{
Mostafa Bellafkih \\ Institut National des Postes et \\ Télécommunications (INPT) \\ Rabat, Maroc
}

\author{
Mohammed Ramdani \\ Département d'informatique \\ FST Mohammedia \\ Mohammedia, Maroc
}

\begin{abstract}
In developing a diagnosis system for detecting student's learning problems, providing intellectual suggestions is helpful and powerful tool to improve the learning performance. However, it is difficult and time consuming for teachers to give personalized suggestions to each student, particularly when there are many students in class. To cope with this problem, this study proposes concept-effect relationship model (CER) as a tool to identify the learning problem of students. Based on that, an intellectual learning guidance system has been proposed.
\end{abstract}

\section{General Terms}

Intelligent Tutoring system

\section{Keywords}

Fussy set theory; Bayesian network; Concept-effect relationship model; learning guidance.

\section{INTRODUCTION}

With vigorous development of the Internet, many scholars have attempted to adopt computer and communication technologies for research on education to support students during their learning performance on the Internet [1], in pursuit of this goal, many systems have been developed. Notable examples include the computer-assisted tutoring and testing systems [2, 3, 4, 5, and 6] and educational diagnosis and guidance systems [7, 8, 9, and 10], specifically, the agent systems for guiding students through on-line course material [11, 12 and 13] and learning feedback during on-line evaluation [7,14] which provide learning suggestions for students after testing.

In recent years, researchers have proposed different approaches for developing adaptive learning systems based on learning behaviors of students during their interaction with e-learning systems [15]. As known, to improve students' learning performance, the teacher should give them additional suggestions. However, it is time consuming for him to give personalized suggestions to each student, particularly when there are many students in class $[1,16]$.

Among the existing models, Concept-effect relationship (CER) has been proved to be an effective way of improving the learning performance of student [1]. The CER model can be used for identifying the learning problem of students, furthermore, takes into account the effect of each concept in the learning process. As result of that, it has been used to successfully give personalized suggestions to them for several scientific courses [17, 18]. In this study, we propose an innovation learning strategy based on CER model and fuzzy set theory that can be used for providing intellectual guidance via elearning environments.

\section{LEARNING GUIDANCE STRATEGY}

\subsection{Concept-Effect Model}

In the CER model, the diagnosis of student learning problems mainly depends on the prerequisite relationships between the concepts to be learned. During tutoring, students learn new concepts among previously learned concepts, from this standpoint, the effect of learning one concept on the learning of other concepts called "Concept-effect relationships".

Consider two concepts to be learned, say $\mathrm{C}_{\mathrm{i}+1}$ and $\mathrm{C}_{\mathrm{i}+2}$ (see Fig.1). If $\mathrm{C}_{i+1}$ is a prerequisite to efficiently performing the more complex and higher level concept $\mathrm{C}_{i+2}$, then a concepteffect relationship " $\mathrm{C}_{\mathrm{i}+1} \rightarrow \mathrm{C}_{\mathrm{i}+2}$ " is said exist with effect " $W_{C_{i+1}, C_{i+2}}$ ", where the " $W_{C_{i+1}, C_{i+2}}$ ", is the relevance degree between $\mathrm{C}_{\mathrm{i}+1}$ and $\mathrm{C}_{\mathrm{i}+2}$ (see section 2.2). From this standpoint, if a student fails to answer most of the test items concerning " $\mathrm{C}_{i+2}$ " due to a lack of understanding of the questions posed or because of carelessness, the problem is likely because the student has not thoroughly learned " $\mathrm{C}_{\mathrm{i}+2}$ " or its prerequisite concepts " $\mathrm{C}_{\mathrm{i}}$ " or " $\mathrm{C}_{\mathrm{i}+1}$ ". Therefore, teachers could identify the learning problems of students by tracing the concept-effect relationships.

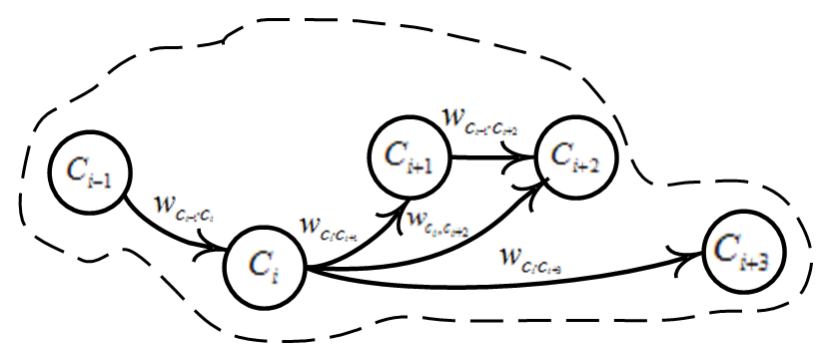

Fig 1: Illustrative example of concept maps

In the CER model, all of the possible learning paths will be taken into consideration to find the poorly-learning paths. In the illustrative example given in Fig.1, to learn concept " $\mathrm{C}_{\mathrm{i}+2}$ ", there are two learning paths for the subject unit:

$$
\begin{aligned}
& \text { PATH 1: } \mathrm{C}_{\mathrm{i}-1} \rightarrow \mathrm{C}_{\mathrm{i}} \rightarrow \mathrm{C}_{\mathrm{i}+1} \rightarrow \mathrm{C}_{\mathrm{i}+2} \\
& \text { PATH 2: } \mathrm{C}_{\mathrm{i}-1} \rightarrow \mathrm{C}_{\mathrm{i}} \rightarrow \mathrm{C}_{\mathrm{i}+2}
\end{aligned}
$$

A threshold " $\theta$ ", is used to indicate the acceptable error rate. If the ratio of incorrect answers to the total strength of concept is less than the proposed threshold, the student is said to have learned concept; otherwise, the student is said to have failed to learn concept and thus the concept is added to the To-BeEnhanced learning path [1]. Among the To-Be-Enhanced learning paths, those with the maximum weight are defined as the critical learning paths that students are asked to restudy it in 
more detail before learning other concepts. In the next section, we propose a probabilistic approach to calculate the error ratio for each student to answer the items related to each concept.

\subsection{Probability Approach for calculating the error ratio}

Let the test portfolio of the learners and the conceptual weight relationships into the matrix $\mathrm{G}$ and the matrix $\mathrm{QC}$, where matrix "G" given as follows:

$$
\begin{aligned}
& \begin{array}{llll}
\mathrm{S}_{1} & \mathrm{~S}_{2} & \ldots & \mathrm{S}_{\mathrm{n}}
\end{array} \\
& G=\begin{array}{c}
\mathrm{Q}_{1} \\
\mathrm{Q}_{2} \\
\vdots \\
\mathrm{Q}_{\mathrm{m}}
\end{array}\left[\begin{array}{ccccc}
g_{11} & g_{12} & \cdots & g_{1 n} \\
g_{21} & g_{22} & \cdots & g_{2 n} \\
& \vdots & \vdots & \ddots & \vdots \\
g_{m 1} & g_{m 2} & \cdots & g_{m n}
\end{array}\right]
\end{aligned}
$$

, where " $\mathrm{g}_{S_{i}, Q_{j}}$ " denotes the score of question " $Q_{j}$ " of the learner " $\mathrm{S}_{\mathrm{i}}$ ", $\mathrm{g}_{\mathrm{S}_{\mathrm{i}}, \mathrm{Q}_{\mathrm{j}}}=1$ denotes the student " $\mathrm{S}_{\mathrm{i}}$ " gets the right answer in question " $\mathrm{Q}_{\mathrm{j}}$ " , and $\mathrm{g}_{\mathrm{S}_{\mathrm{i}}, \mathrm{Q}_{\mathrm{j}}}=0$ denotes the student " $\mathrm{S}_{\mathrm{i}}$ " has a wrong answer in question " $\mathrm{Q}_{\mathrm{j}}$ ", $1 \leq i \leq n$ and $1 \leq j \leq m$, " $\mathrm{n}$ " is number of learners and " $\mathrm{m}$ " is number of questions. Furthermore, let the questions-concepts matrix shown as follows:

$$
\mathrm{QC}=\begin{array}{ccccc}
\mathrm{C}_{1} & \mathrm{C}_{2} & \ldots & \mathrm{C}_{\mathrm{p}} \\
\mathrm{Q}_{1} \\
\mathrm{Q}_{2} \\
\vdots \\
\mathrm{Q}_{\mathrm{m}}
\end{array}\left[\begin{array}{ccccc}
\mathrm{qc}_{11} & \mathrm{qc}_{12} & \ldots & \mathrm{qc}_{1 \mathrm{p}} \\
\mathrm{qc}_{21} & \mathrm{qc}_{22} & \ldots & \mathrm{qc}_{2 \mathrm{p}} \\
& \vdots & \vdots & \ddots & \vdots \\
\mathrm{qc}_{\mathrm{m} 1} & \mathrm{qc}_{\mathrm{m} 2} & \ldots & \mathrm{qc}_{\mathrm{mp}}
\end{array}\right]
$$

, where " $q c_{i j}$ " denotes the weighting or degree of relevance for each concept " $\mathrm{C}_{\mathrm{i}}$ " to each question " $\mathrm{Q}_{\mathrm{j}}$ " integrated from multiple experts [19] and $1 \leq \mathrm{qc}_{\mathrm{ij}} \leq 1$.

From the probability viewpoint, the QC matrix can be useful to calculate the probability of failure for a student.

This probability is calculated as the ratio of " $\mathrm{qc}_{\mathrm{ij}}$ " to $\sum_{j=1}^{m} \mathrm{qc}_{\mathrm{ij}}$ Moreover, if the student fails to answer more than one question, then Eq. (1) can be used to calculate failing rates for each concept.

$$
P\left(C_{j}\right)=\frac{\sum_{i=1}^{m}\left(1-\mathrm{g}_{\mathrm{ij}}\right) \times \mathrm{qc}_{\mathrm{ij}}}{\sum_{i=1}^{m} \mathrm{qc}_{\mathrm{ij}}}
$$

, where " $g_{i j}$ "- represents the student's answers for each of the questions and the test set has $m$ questions. If " $\mathrm{g}_{\mathrm{ij}}$ " is 1 then the student answers the question " $Q_{j}$ "correctly, otherwise " $g_{i j}$ " $=0$.

To illustrate how CER model works, let student's answer vector be $\overrightarrow{g_{i j}}=\langle 1,1,1,0,1,0,1,1,0,0\rangle$ for $\mathrm{m}=10$ and QC matrix is as follows:

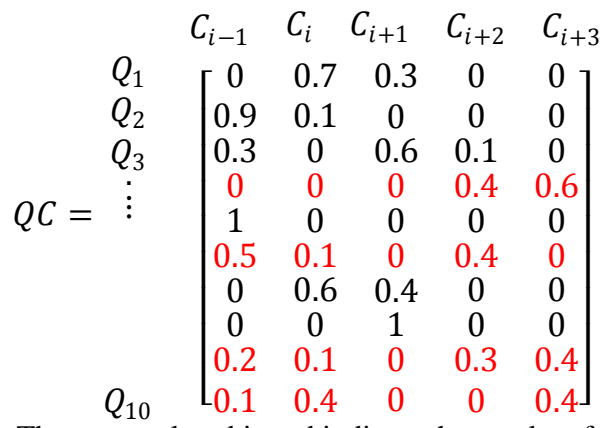

(Note: The rows colored in red indicate that student failed to answer question correctly)

Then using Eq.(1) and QC matrix, it will be known, that the student will fail to answer $27 \%$ of questions related to the concept " $\mathrm{C}_{\mathrm{i}-1}$ ", $30 \%$ of questions related to the concept " $\mathrm{C}_{\mathrm{i}}$ ", $0 \%$ of questions related to the concept " $\mathrm{C}_{i+1}$ ", $92 \%$ of questions related to the concept " $\mathrm{C}_{\mathrm{i}+2}$ " and $100 \%$ of questions related to the concept " $\mathrm{C}_{\mathrm{i}+3}$ ".

\subsection{Calculation Relevance Degree between Concepts}

Concepts and concepts map play an important role in this study. Researchers argue that the notion of concept can be thought of as an atomic unit of knowledge and this knowledge is created by forming connections among concepts [20]. Moreover, each course unit is made up of a certain number of related concepts, and each concept has its own size and its own special importance or effect in other concepts. In [21], we proposed an approach to construct concept map and calculated the relevance degree between concepts based on the corresponding relation of concepts and questions (Question-concepts matrix) to explore the degree of student familiarization with the concepts, according to collected data from the students' assessment records where the relevance degree between concepts determine as follows:

$$
W\left(C_{i} \rightarrow C_{j}\right)=\operatorname{Max}\left(W_{Q_{x} C_{i}} \times W_{Q_{y} C_{j}} \times \operatorname{Conf}\left(Q_{x} \rightarrow Q_{y}\right)\right)
$$

, where " $W\left(C_{i} \rightarrow C_{j}\right)$ "denotes the relevance degree of the relationship " $C_{i} \rightarrow C_{j}$ " converted from the relationship

" $Q_{x} \rightarrow Q_{y}$ ", " $W_{Q_{x} C_{i}}$ "denotes the weight of the concept " $C_{i}$ " in the question " $Q_{x}$ ", " $W_{Q_{y} C_{j}}$ "denotes also the weight of the concept " $C_{j}$ " in the question " $Q_{y}$ ", and $\operatorname{Conf}\left(Q_{x} \rightarrow Q_{y}\right)$ denotes the confidence of the relationship " $Q_{x} \rightarrow Q_{y}$ " obtained by Apriori Algorithm [22].

Using the proposed approach provides us a visual knowledge representations, which show relationships among concepts as standardized learning order of different concepts, effect between it and can also serve as a tool of detect the learning barriers.

\section{INTELLECTUAL LEARNING GUIDANCE SYSTEM}

This study proposes a combination of Bayesian networks (also known as belief networks or Bayes nets for short) and CER model to provide learning guidance, which uses concept map as a tool for representation domain knowledge. 


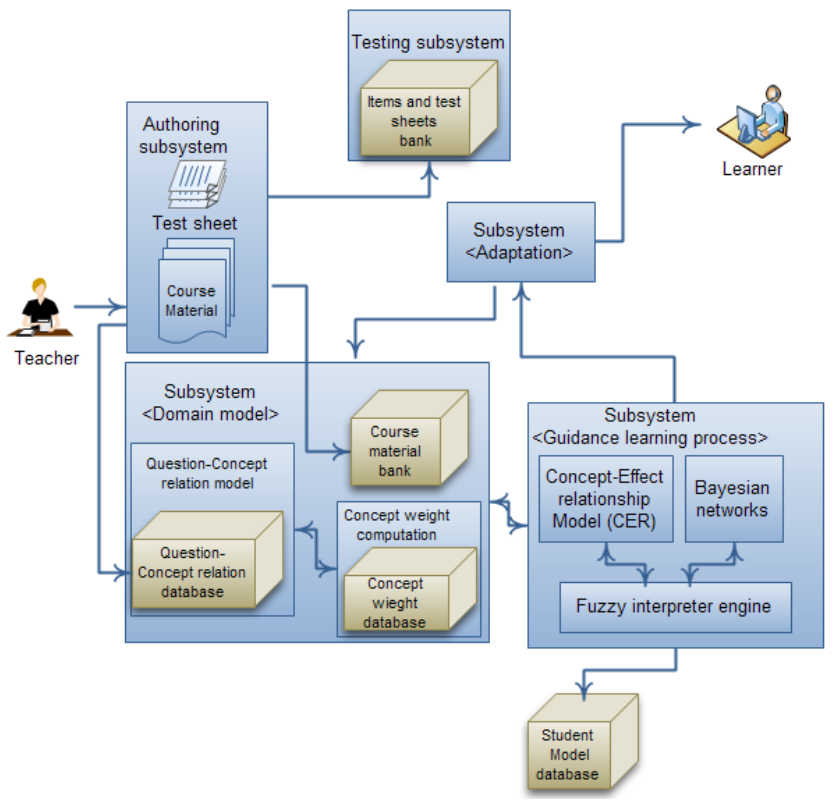

Fig 2: System architecture

The architecture of system is depicted in Fig.2, which has five major subsystems/functional modules, including the authoring subsystem, testing subsystem, "domain model", subsystem "Adaptation" and subsystem "guidance learning process".

The details of each module/subsystem are described as follows:

1. Authoring subsystem: This subsystem is responsible for creating (i.e. teacher/tutor) courses content and setting the weight of each concept to each question.

2. Testing subsystem/module: This module is responsible for providing evidence about what learner knows and his knowledge level/background. Moreover, it used for mining relationships between concepts in domain model.

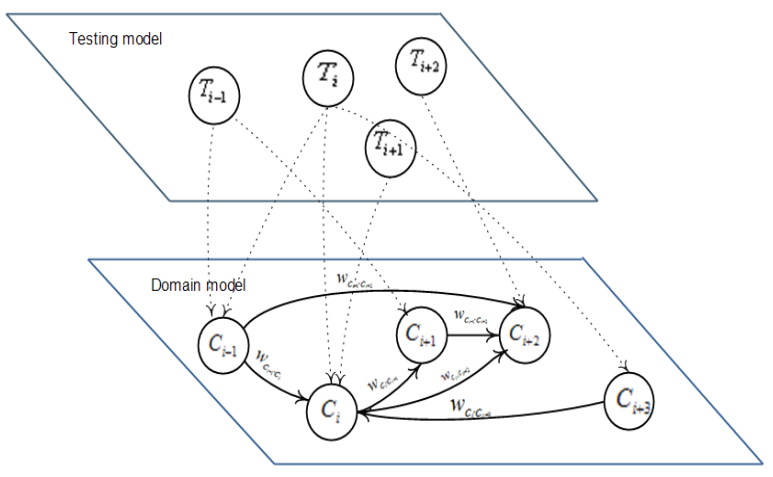

Fig 3: Relationship between Testing model and Domain model.

3. Domain model: This subsystem contains questionconcept relation computation module and concept weight computation module.

- The question-concept relation computation module used to set the relationship between the concepts appeared in test sheets by teacher or domain expert.
- The concept weight computation module used to compute the weight or the relevance degree of each concepts using formula (2), which represent the Strength of effect is (for more derail see algorithm described in [20].

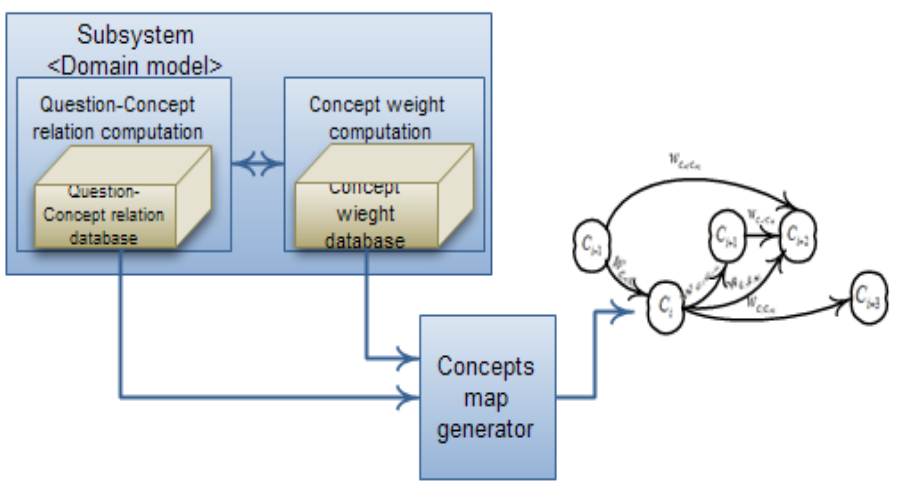

Fig 4: Process constructing concepts map.

Both question-concept relation computation module and concept weight computation module collaborate together to generate concept maps that display relationships and concepts nodes.

4. Adaptation subsystem: This module is responsible for representing content and necessary adaptation. Adaptation algorithm in this context belongs to behavioral class model that means it is reactive with current student's knowledge level [23] and conceptual weight.

5. Subsystem "Guidance learning process": This module is essential part in the proposed system, where concepteffect relationship model which used to detect learning problem and Bayesian networks to provide forward guidance. Moreover, to make the learning guidance more understandable to student and tutor/teacher, the fuzzy set theory is proposed. Let the four membership functions are proposed as shown in Fig. 5.

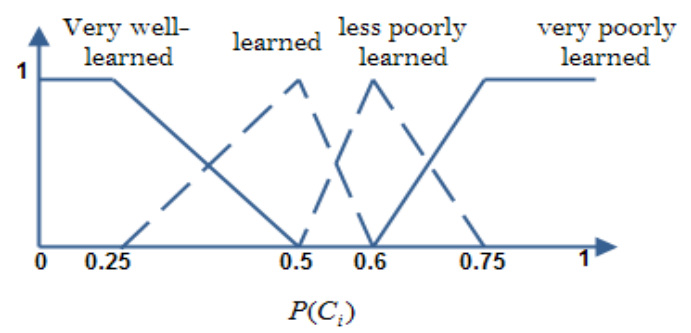

Fig 5: The given membership functions

According to the demonstration was proposed in section 2.2, it can be seen that the student does not understand the concepts " $C_{i+2}$ " and " $C_{i+3}$ " because the $P\left(C_{i+2}\right)=0.92$ and $P\left(C_{i+3}\right)=1$, where student's learning status is very poorly learned (see Fig.5). For that reason to provide teaching suggestions to student system advice him to restudy the related concepts. Assuming that the teacher has defined the acceptable error ratio to be 0.2 , as seen in Fig.1, it can easily determine the related concepts $\left(C_{i-1}, C_{i}\right.$ and $\left.C_{i+1}\right)$ however, concept " $C_{i+1}$ "learned 
very well, thus both concepts " $C_{i-1}$ " and " $C_{i}$ " are assigned as misunderstanding of concepts " $C_{i+2}$ " and " $C_{i+3}$ "; moreover, the student should learn " $C_{i-1}$ " before learning " $C_{i}$ ", this does not represent that the learner does not understand " $C_{i-1}$ " at all. It means that it is very probably that the learner has not fully understood a part it only. Therefore, concept " $C_{i-1}$ " will be strongly recommended.

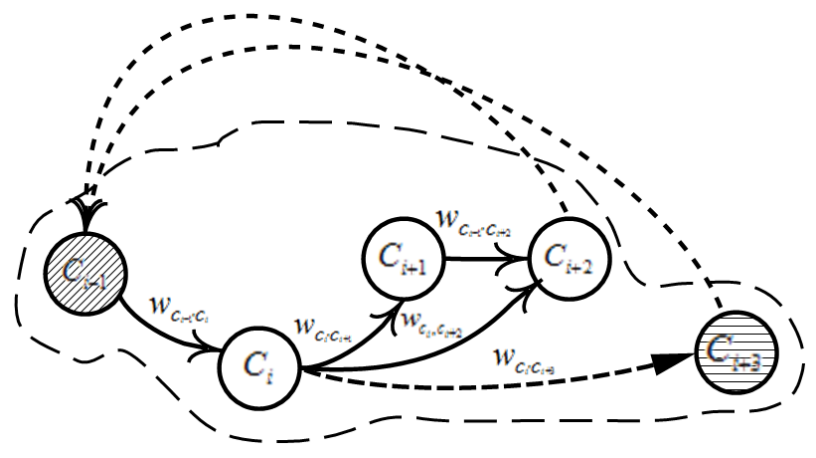

Fig 6: learning suggestion based on the concept-effect relationship model.

\section{CONCLUSIONS}

In recent years, researchers have proposed different approaches for developing adaptive learning systems based on learning behaviors of students during their interaction with e-learning systems. To improve the learning achievement of students, it is important to diagnose the learning problem and provide learning suggestions for individual students. In the last decade, several studies have been conducted for diagnosing student learning problems and providing appropriate learning guidance for individual students [19]. Among the existing models, Concepteffect relationship (CER) has been proved to be an effective way of improving the learning performance of student [1]. However, it is difficult and time consuming for teachers to give personalized suggestions to each student, particularly when there are many students in class. In this study an intellectual guidance system has been proposed to identify the learning problem of students. The next step of our study will be testing this approach with actual students and teachers and observing how it affects their learning performance.

\section{REFERENCES}

[1] G. J. Hwang,"A conceptual map model for developing intelligent tutoring systems", Computers \& Education, vol. 40 , no. 3, pp. $217-235,2003$

[2] C. K. Chiou, G. J. Hwang, and J. C. R. Tseng, "An autoscoring mechanism for evaluating problem-solving ability in a web-based learning environment". Computers \& Education, vol. 53. No. 2, pp. 261-272, 2009.

[3] G. J. Hwang, H. C. Chu, P. Y. Yin, and J. Y. Lin, "An innovative parallel test-sheet composition approach to meet multiple assessment criteria for national tests". Computers\& Education, vol. 51, no. 3, pp.1058-1072, 2008.

[4] J. P. D. Plessis, J. A. V. Biljon, C. J. Tolmie, and T. Wollinger, "A model for intelligent computer-aided education systems". Computers \& Education, vol. 24, no. 2, pp. 89-106, 1995.
[5] C. R. Springer, and J. J. Pear, "Performance measures in courses using computer-aided personalized system of instruction". Computers \& Education, vol. 51, no.2, pp.829-835, 2008.

[6] C.-L. Hung, and Y.W. Hung, "A Practical Approach for Constructing an Adaptive Tutoring Model Based on Concept Map", VECIMS 2009 - International Conference on Virtual Environments, Human-Computer Interfaces and Measurements Systems Hong Kong, China May 11-13, 2009.

[7] C. C. Tsai, and C. Chou, "Diagnosing students' alternative conceptions in science". Journal of Computer Assisted Learning, vol. 18, no. 2, pp.157-165, 2002.

[8] G. J. Hwang, H. C. Cheng, H. C. Chu, J. C. R. Tseng, and G. H. Hwang, "Development of a web-based system for diagnosing student learning problems on English tenses". Journal of Distance Education Technologies, vol.5, no. 4, pp.80-98, 2007.

[9] C. H. Lee, G. G. Lee, and Y. Leu, "Application of automatically constructed concept map of learning to conceptual diagnosis of e-learning". Expert Systems with Applications, vol. 36, no. 2, 1675-1684, 2009.

[10] S. Hooper, "Cooperative learning and computer-based instruction". Educational Technology Research \& Development, vol. 40, no. 3, pp. 21- 38, 1992.

[11] B. Ozdemir, and F. Alpaslan, "An intelligent tutoring system for student guidance in Web-based courses". $4^{\text {th }}$ International Conference on Knowledge-based Intelligent Engineering System and Allied Technologies, vol. 2, pp.835-839, 2000

[12] C.J. Butz, S. Hua, and R.B. Maguire, "A Web-based Bayesian Intelligent Tutoring System for Computer Programming". Evolution of the Web in Artificial Intelligence Environments, pp. 221-242, Springer-Verlag Berlin Heidelberg, 2008.

[13] G. J. Hwang, "A test-sheet-generating algorithm for multiple assessment requirements". IEEE Transactions on Education, vol. 46, no.3, pp.329-337,2003.

[14] G. J. Hwang, P. S. Tsai, C. C. Tsai, and J. C. R. Tseng, "A novel approach for assisting teachers in analyzing student web-searching behaviors". Computers \& Education, vol. 51, no. 2, pp.926-938, 2008.

[15] G. J. Hwang, C. L. Hsiao, and J. C. R. Tseng, "A computerassisted approach to diagnosing student learning problems in science courses". Journal of Information Science and Engineering, vol. 19, no. 2, pp.229-248,2003.

[16] B. S. Jong, T. W. Lin, Y. L. Wu, and T. Y. Chan, "Diagnostic and remedial learning strategy based on conceptual graphs". Journal of Computer Assisted Learning, vol. 20, no. 5, pp.377-386, 2004.

[17] H.C. Chu, G.J. Hwang, Judy C. R. Tseng, and G.H. Hwang, "A Computerized Approach to Diagnosing Student Learning Problems in Health Education". Asian Journal of Health and Information Sciences, Vol. 1, No. 1, pp. 43-60, 2006.

[18] K. GÜNEL, and R. AȘLIYAN, "Determining Difficulty Of Questions In Intelligent Tutoring Systems". The Turkish Online Journal of Educational Technology - TOJET ISSN: 1303-6521, vol. 8, no. 3, pp.14-21, July, 2009.

[19] P., Panjaburee, G. J., Hwang, W., Triampo, and B. Y., Shih. "A multi-expert approach for developing testing and 
diagnostic systems based on the concept-effect model" Computers \& Education. Vol. 55,pp. 527-540.2010

[20] C.,Hsu, R.,Kuo, M.,Chang, and J.,Heh, "Implementing a Problem Solving System for Physics based on Knowledge map and Four Steps Problem Solving Strategies". 2ed international Conference on Advanced Learning Technologies, 2002.

[21] M.,Al-Sarem, M.,Bellafkih, M., Ramdani, “ A New Method for Constructing Concept Maps in E-Learning Systems". Advanced Research on Computer Education,
Simulation and Modeling, SpringerVerlag,Vol.176,no.2,pp.180-185.2011.

[22] R., Agrawal, and R., Srikant, Fast algorithms formining association rules, In Proceedings of the 20th International Conference on Very Large Database, pp.487-499.1994

[23] O.A., Shabalina "Models and methods of modeling learning process".Ph.D thesis, University of Astrakhan.2005. 